\title{
Comparison of Esterifying Ability of Some Lipases
}

\author{
V.S. Gamayurova*, Mataz J. Jamai, S.K. Zaripova, K.L. Shnaider, N.I. Bil'danova, M.N. Chernykh \\ Food Biotechnology Department, Kazan National Research Technological University (KNITU), K.Marks Str. 68, Kazan - 420015, Russia.
}

\section{AR T IC LE DET A ILS}

\section{Article history:}

Received 23 January 2018

Accepted 09 February 2018

Available online 20 February 2018

\section{Keywords:}

Lipases

Esterification

Fragrant Substances

Esters

\begin{abstract}
A B S T RAC T
The esterification activity of some commercial lipases was examined. The comparison of the enzymatic activities was carried out in regard to the synthesis of esters of lower aliphatic acids and alcohols. The highest esterifying ability was shown by the enzyme preparation Novozym 435 which quickly starts the process. The conversion of used acids was $70-82 \%$ within 0.5 hours, and reached $90 \%$ of conversion in 1 hour of reaction. Similar efficacy shows Novozym 40086. This enzyme preparation provides $90 \%$ conversion of the acids in two hours of process. The enzyme preparation Lipozyme TLIM provides conversion of the used acids on $84-90 \%$ in three hours of process. The enzyme preparation Lipozyme CALB is less effective on the used acids. Thus, in the synthesis of aliphatic esters the esterifying ability of enzyme preparations in the studied conditions decreases in a row: Novozym 435, Novozym 40086, Lipozyme TLIM, Lipozyme CALB. Pancreatic lipase in the synthesis of butyl butyrate detects an induction period of about 1 hour.
\end{abstract}

\section{Introduction}

In recent years it has sharply increased interest in the enzymatic synthesis of esters of aliphatic acids and alcohols many of which are flavour substances widely used as flavorings in the food industry and perfumery, fragrances in detergent production [1-8].

This increased interest corresponds to the world trend in replacement of the known chemical catalysts on enzymatic ones as the last have a number of ecological, technological and energy advantages. Intensive study of enzymes in recent years and emergence onto the market cheaper enzyme products makes their use promising in industrial scale. This fully applies to such enzyme preparations as lipase. The replacement of the known chemical methods of obtaining flavour substances from the class of esters on enzymatic is attractive and promising not only because of the technological and energy benefits but also because, due to the high specificity of enzymes and low process temperature $\left(20-45^{\circ} \mathrm{C}\right)$, receiving of pure target substance which aren't polluted by by-products requiring special cleaning methods. It is very important for the well-known fields of application (perfumery, the food industry).

In the present work the analysis of synthesis of butyl esters of propionic and butyric acids, and benzylpropionic ether is carried out. These esters are typical aromatic substances: butylpropionate has an ether-fruity smell with mushroom shade, benzylpropionate has a fruity-floral smell with a hint of jasmine, and butylbutyrate has strong sweet-fruity smell with note of overripened bananas [9].

The main goal of this work is the elucidation of ability of a number of commercial lipases to carry out the esterification processes and comparison of their synthesize activity. As a catalysts, the enzymes of the company Novozymes - Lipozyme TLIM, Lipozyme CALB, Novozym 435 and Novozym 40086 (Denmark), as well as Lipase from porcine pancreas, Type II (USA) are used. The choice of enzymes is determined by the fact that they are produced industrially and therefore relatively affordable. These enzymes are mainly intended for the implementation of the processes of transesterification.

\section{Experimental Methods}

Lipases

1. Novozym 435 - unspecific lipase, immobilized, optimal conditions of use 30-60 ${ }^{\circ} \mathrm{C}, \mathrm{pH} 5-9$;
2. Novozym 40086 - 1, 3 lipase, immobilized, optimal conditions of use 30$50{ }^{\circ} \mathrm{C}, \mathrm{pH}$ 7-10;

3. Lipozyme TLIM - 1, 3 lipase, immobilized, optimal conditions of use 50 $75^{\circ} \mathrm{C}, \mathrm{pH} 6-8$;

4. Lipozyme CALB - unspecific lipase, liquid, optimal conditions of use 30 $60{ }^{\circ} \mathrm{C}, \mathrm{pH} 5-9$;

5. Commercial preparation Lipase from porcine pancreas, Type II lyophilized, Activity - 100-500 units/mg protein (USA).

Used substrates - aliphatic acids (propionic, and butyric) and alcohols ( $n$-butanol,and benzyl alcohol) - were reagent grade. As the solvent it was used hexane (reagent grade) with temperature of boiling $69^{\circ} \mathrm{C}$.

The acids were used in $0.1 \mathrm{~N}$ concentration. Molar ratio acid: alcohol varied from $1: 1.1$ to $1: 2$.

The synthesis was carried out at $30{ }^{\circ} \mathrm{C}$ and $35{ }^{\circ} \mathrm{C}$, the duration of the process varied from 0.25 to 30 hours. The amount of enzyme in the reaction mixture was $10 \mu \mathrm{L} / \mathrm{mL}, 20 \mu \mathrm{L} / \mathrm{mL}, 30 \mu \mathrm{L} / \mathrm{mL}$.

Control of process of esterification was carried out by titration of residual acid with a $0.1 \mathrm{~N}$ alcoholic solution of $\mathrm{NaOH}$ (in $80 \%$ alcohol) in the presence of indicator ( $1 \%$ alcohol solution of phenolphthalein). The acid conversion (B) was calculated by the formula: $\mathrm{B}=(\mathrm{K}-\mathrm{O} / \mathrm{K}) 100 \%$, where $\mathrm{K}$ is the amount of alkali solution that went to titration of the control, $\mathrm{O}$ is the amount of alkali solution that went into titration of the sample.

After the process was complete the enzyme was separated from the reaction mass, an excess of alcohol and hexane removed by vacuum distillation. The formation of the ether was confirmed by the IR spectrum recorded on a Fourier spectrometer "Infra-LUM FE-80" (Perkin Elmer) in $4000-400 \mathrm{~cm}^{-1}$ diapason. The refractive index nD20 detected on the Refractometer IRF-20.

All experiments were made in six replicates. The data were processed by means of applied software package Statistica. The relative error was not more than $6.3 \%$.

\section{Results and Discussion}

In the synthesis of butylpropionate three lipases of the company Novozymes - Novozym 435, Novozym 40086 and Lipozyme TLIM - were used. Kinetic curves of enzymatic synthesis of butylpropionate when using three enzyme preparations are given in Figs. 1 and 2. In all cases the process conditions were the same: concentration of acid of $0.1 \mathrm{~N}$, the molar ratio of acid:alcohol as $1: 2$, process temperature $30^{\circ} \mathrm{C}$, solvent hexane, the concentration of enzymes $10 \mathrm{mg} / \mathrm{mL}$ (Fig. 1) or $20 \mathrm{mg} / \mathrm{mL}$ (Fig. 2). The 
process of esterification carried out in an organic solvent hexane, as it was shown earlier that it has the least inhibitory effect on enzyme preparations [6]. These data show that all the enzymes are capable effectively to catalyze process of etherification of propionic acid with butanol. The highest esterifying ability is shown by the enzyme preparation Novozym 435 which in 30 min of process provides conversion of the acid from 74 to $82 \%$ depending on concentration of enzyme. Slightly lower efficiency demonstrates the preparation Novozym 40086. It provides 61 and 70\% conversion of the acid during the first $3 \mathrm{~min}$ of the process, respectively. In 2 hours of speed of these enzymes are equalized and practically process comes to the end with conversion of $90 \%$. After 3 hours all three enzymes finish process at the same level, conversion of propionic acid makes $92 \%$.

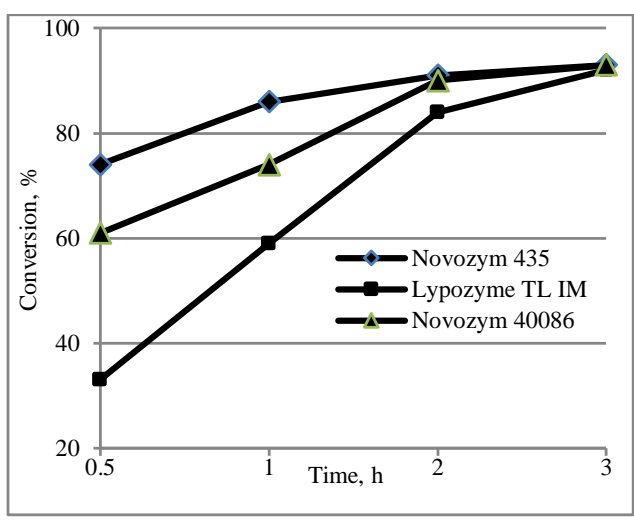

Fig. 1 The esterifying ability of the Novozym 435, Lypozyme TL IM and Novozym 40086 preparations in the synthesis of butylpropionate ether, $\mathrm{T}=30^{\circ} \mathrm{C}$, enzyme concentration $10 \mathrm{mg} / \mathrm{mL}$

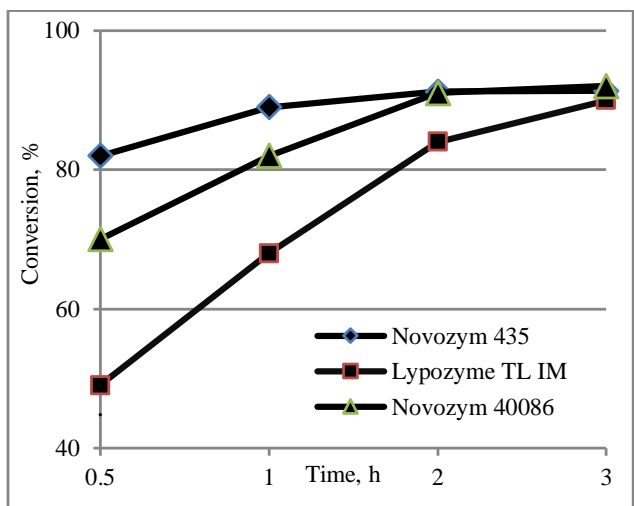

Fig. 2 The esterifying ability of the Novozym 435, Lypozyme TL IM and Novozym 40086 preparations in the synthesis of butylpropionate ether, $\mathrm{T}=30^{\circ} \mathrm{C}$, enzyme concentration $20 \mathrm{mg} / \mathrm{mL}$

Considering that enzyme Novozym 435 is an excellent catalyst for the esterification of propionic acid with butyl alcohol a half the concentration of the lipase was used. After 30 min from the start of the reaction, the conversion of the propionic acid is equal to $70 \%$, and after 4 hours the process is almost complete and the conversion comes up to $92 \%$ (Table 1 ).

Table 1 Butylpropionate synthesis by the enzyme preparation Novozym 435

\begin{tabular}{ll}
\hline Time duration, $\mathrm{h}$ & Acid conversion, \% \\
\hline 0.5 & $70 \pm 0.1$ \\
1 & $77 \pm 0.07$ \\
2 & $87 \pm 0.06$ \\
3 & $89 \pm 0.06$ \\
4 & $92 \pm 0.05$ \\
\hline \multicolumn{2}{l}{ The acids were used in $0.1 \mathrm{~N}$ concentration, molar ratio acid: alcohol 1:2, hexane as a } \\
solvent, temperature $30^{\circ} \mathrm{C}$, concentration of enzyme $-5 \mathrm{mg} / \mathrm{mL}$
\end{tabular}

solvent, temperature $30^{\circ} \mathrm{C}$, concentration of enzyme $-5 \mathrm{mg} / \mathrm{mL}$

Comparison of esterifying ability of other pair of enzyme preparations, Lipozyme TLIM and Lipozyme CALB, has been carried out at of the substrates benzyl alcohol and propionic acid. Fig. 3 shows kinetic curves of obtaining benzylpropionate when the enzyme Lipozyme TLIM in its various concentrations, the concentration of acid of $0.1 \mathrm{~N}$, the molar ratio acid:alcohol of $1: 1.1$, process temperature $35{ }^{\circ} \mathrm{C}$, solvent hexane. As can be seen from these data, the conversion of the acid during the initial stages https://doi.org/10.30799/jacs.179.18040102

Cite this Article as: V.S. Gamayurova, M.J. Jamai, S.K. Zaripova, K.L. Shnaider, N.I. Bil'danova, M.N. Chernykh, Comparison of esterifying ability of some lipases, J. Adv. Chem. Sci. 4(1) (2018) 531-533. of synthesis is higher at higher concentrations of enzyme, but after 2.5 hours the process is leveled with conversion of acid of $82-85 \%$.

Fig. 4 shows the kinetic curves for the synthesis of benzylpropionate involving enzyme preparations Lipozyme TLIM and Lipozyme CALB. As can be seen, enzyme preparation Lipozyme TLIM much more efficiently catalyses the synthesis of benzylpropionate than Lipozyme CALB, which after 4 hours of esterification converts propionic acid at $40 \%$, while Lipozyme TLIM at $85 \%$.

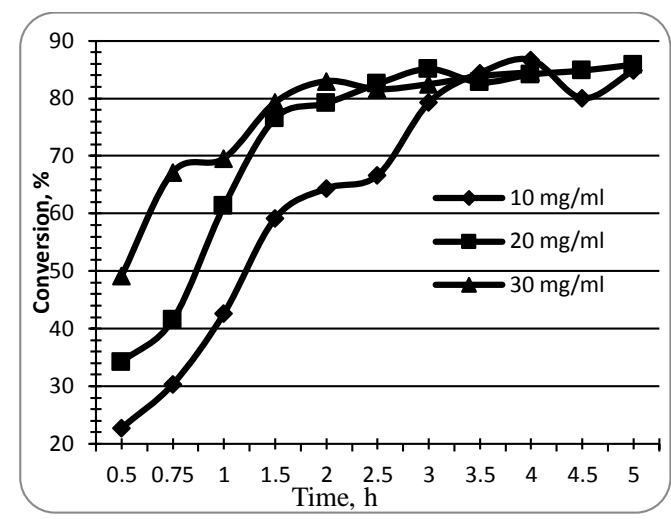

Fig. 3 The esterifying ability of Lipozyme TLIM preparations in the synthesis of benzylpropionate ether, $\mathrm{T}=35^{\circ} \mathrm{C}$, enzyme concentration 10 20 , and $30 \mathrm{mg} / \mathrm{mL}$

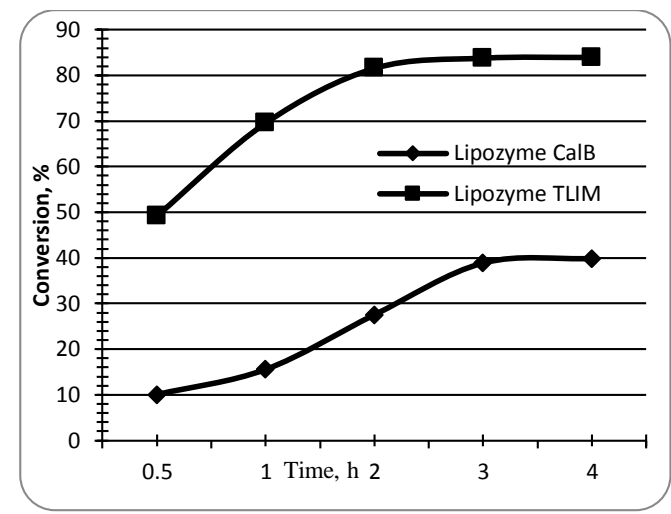

Fig. 4 The esterifying ability of Lipozyme TLIM ( $30 \mathrm{mg} / \mathrm{mL})$ and Lipozyme CALB (30 $\mathrm{mkl} / \mathrm{mL}$ ) in the synthesis of benzylpropionate ether

Esterification of the other pair of substrates - butyl alcohol and butyric acid was analyzed using the enzyme Lipozyme TLIM, Lipozyme CALB and pancreatic lipase. Figs. 5 and 6 shows these results. Esterification was carried out in hexane solution, acid concentration of $0.1 \mathrm{~N}$, the molar ratio of acid:alcohol was 1:2. These data also show higher esterifying ability of enzyme Lipozyme TLIM for substrates butyl alcohol - butyric acid, which after a 4 hour of the process provides $90 \%$ conversion of the acid, while Lipozyme CALB no more than $68 \%$. As for a pancreatic lipase, apparently from Figs. 5 and 6, it detects an induction period of about 1 hour when the process doesn't go, and only after 24 hours of esterification the conversion of the acid reaches $90 \%$.

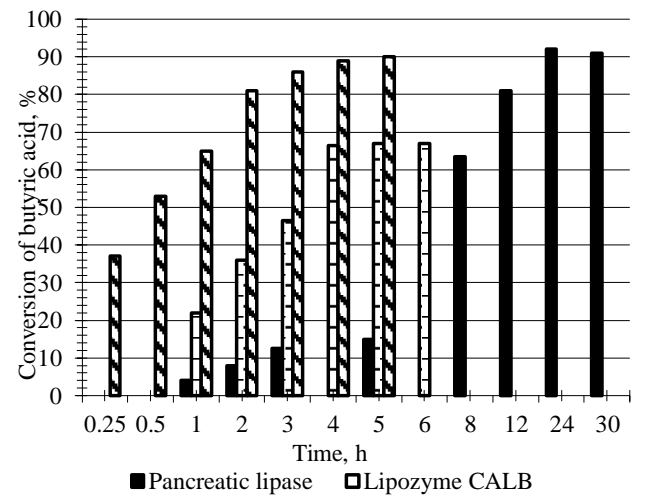

Fig. 5 The esterifying ability of Lipozyme TLIM $(20 \mathrm{mg} / \mathrm{mL})$ and Lipozyme CALB $(20$ $\mathrm{mkl} / \mathrm{mL})$, and pancreatic lipase $(10 \mathrm{mg} / \mathrm{mL})$ in the synthesis of butylbutyrate ether 


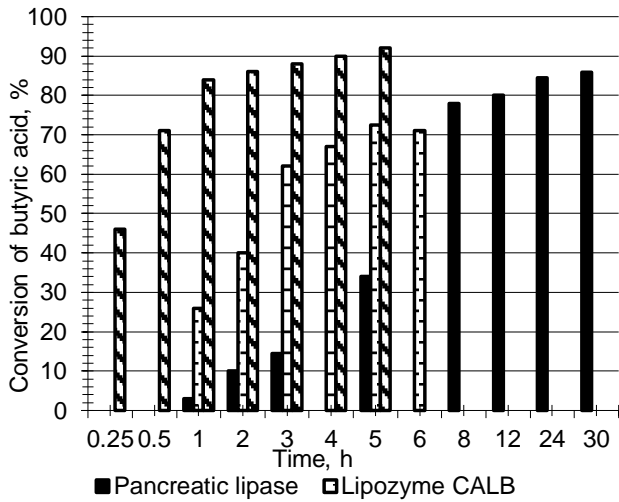

Fig. 6 The esterifying ability of Lipozyme TLIM $(20 \mathrm{mg} / \mathrm{mL})$ and Lipozyme CALB (20 $\mathrm{mkl} / \mathrm{mL})$, and pancreatic lipase $(20 \mathrm{mg} / \mathrm{mL})$ in the synthesis of butylbutyrate ether

These data also show higher esterifying ability of enzyme Lipozyme TLIM for substrates butyl alcohol - butyric acid, which after 4 hours of the process provides $90 \%$ conversion of the acid, while Lipozyme CALB no more than $68 \%$. As for a pancreatic lipase, apparently from Figs. 5 and 6 , it detects an induction period of about 1 hour when the process doesn't go, and only after 24 hours of esterification the conversion of the acid reaches $90 \%$.

After isolation of the ethers, IR spectra were recorded. Table 2 shows the characteristic frequencies of stretching vibrations of synthesized esters, carbonyl $\mathrm{v}_{\mathrm{C}}=0$ and ester bonds $\mathrm{v}_{\mathrm{C}-0}$, as well as their refractive indices. These data confirm the obtainment of the target products and their purity.

Table 2 IR spectrum and refractive indices of synthesized ethers

\begin{tabular}{|c|c|c|c|c|}
\hline \multirow[t]{2}{*}{ Ether } & \multicolumn{2}{|c|}{ Characteristic frequencies } & \multicolumn{2}{|l|}{$\mathrm{n}_{\mathrm{D}}^{20}$} \\
\hline & $\mathrm{U}_{\mathrm{C}=0 \mathrm{CM}^{-1}}$ & $\mathrm{U}_{\mathrm{C}-0} \mathrm{CM}^{-1}$ & Experimental & Ref. $[9,10]$ \\
\hline butylbutyrate & 1735.9 & 1178.1 & 1.4050 & 1.4049 \\
\hline butlpropionate & 1736.6 & 1182.1 & 1.4000 & 1.4001 \\
\hline benzylpropionate & 1736.5 & 1171.6 & 1.5000 & 1.4996 \\
\hline
\end{tabular}

${ }^{*}$ stretching vibrations $v_{C=0}$ of butyric acid $1705.9 \mathrm{~cm}^{-1}$, of propionic acid $1708.5 \mathrm{~cm}^{-1}$

\section{Conclusion}

All used lipases are able to catalyze the esterification of lower aliphatic acids and alcohols, though lipases of the Novozymes Company applyed in experiments are mainly recommended for transesterification and stereoselective hydrolysis of esters. The rate of the esterification process is different. The best results for the analyzed substrates butanol-propionic acid in the experimental conditions are shown by the enzyme preparation Novozym 435 , which very quickly starts the process. It provides 70 to $82 \%$ of conversion within 0.5 hours depending on the enzyme concentration, and in one hour the process reaches about $90 \%$ conversions. Close results are shown by the Novozym 40086 enzyme preparation which in 2 hours of the process provides conversion of acid of $90 \%$. The enzyme preparation Lipozyme TLIM in these experiments only in 3 hours of process gives conversion about $90 \%$.

The same Lipozyme TLIM enzyme in similar conditions for other pairs of substrates butanol-butyric acid and benzyl alcohol-propionic acid in 3 hours of process provides $84-86 \%$ of conversion of the acid.

Enzyme preparation Lipozyme CALB has a lower esterifying ability and in the synthesis of benzylpropionate conversion reaches only $40 \%$ in 4 hours of the process.

Based on these data, it is possible to present that at the synthesis of aliphatic esters the efficiency of enzyme preparations in the studied conditions decreases among: Novozym 435, Novozym 40086, Lipozyme TLIM, Lipozyme CALB.

Pancreatic lipase in the synthesis of butyl butyrate has an induction period of 1 hour, when the esterification process practically does not go, but within 24 hours it provides $90 \%$ conversion.

\section{Reference}

[1] Yicheng Bi, Min Yu, Hai-Jan Zhou, Hua Zhou, Ping Wei, Biosynthesis of oleyl oleate in solvent-free system by Candida rugose Lipase (CRL) immobilized in macroporous resin with cross-linking of aldehyde-dextran, J. Mol. Catal. B: Enzym. 133 (2016) 1-5.

[2] R. Berger, Biotechnology of flavours - the next generation, Biotechnol. Lett. 31 (2009) 1651-1659.

[3] M.A. Longo, M.A. Sanroman, Production of food aroma compounds: microbial and enzymatic methodologies, Food Technol. Biotechnol. 44 (2006) 335-353.

[4] Zorica Knezevic-Jucovic, Dejan Bezbradica, Zivana Jackovejevic, Dusan Mijan, Lipase catalyzed synthesis of flavor esters in non-aqueous media: Optimization of the yield of pentyl 2-methylpropionate by statistical analysis, J. Serbian Chem Sociate. 73(12) (2008) 1139-1151.

[5] Pooja Singh, Devesh K. Saxena, S.N. Naik, Synthesis of food by enzymatic esterification process, Int. J. Sci. Res. 3(9) (2014) 2123-2116.

[6] V.S. Gamayrova, K.L. Shnaider, M.J. Jamai, Enzymatic synthesis of butirates of fusel oil, Catal. Indust. 9(1) (2017) 85-90.

[7] V.S. Gamayurova, K.L. Shnaider, S.K. Zaripova, M.J. Jamai, Synthesis of aliphatic flavoring substances by lipase, J. Adv. Chem. Sci. 2(2) (2016) 259-260.

[8] V.S. Gamayurova, Mataz J. Mataz, M.N. Chernykh, S.K. Zaripova, The influence of acyl donators on the enzymatic activity of lipase Lipozyme CALB in the esterification process, J. Adv. Chem. Sci. 3(2) (2017) 478-479.

[9] S.A. Vojtkevich, 865 flavoring substances for perfumes and household chemicals, Pystchevaya promyshlennost, Moscow, 1994, 593.

[10] Anonymous, The Reference Book of the Chemist, 2 ${ }^{\text {nd }}$ Ed., Vol.IV, Chemistry, Moscow, 1965, pp. 821-893. 